\title{
Protective immunization of horses with a recombinant canarypox virus vectored vaccine co-expressing genes encoding the outer capsid proteins of African horse sickness virus
}

\author{
Alan J. Guthrie ${ }^{a}$, Melvyn Quan ${ }^{\mathrm{a}}$, Carina W. Lourens ${ }^{\mathrm{a}}$, Jean-Christophe Audonnet ${ }^{\mathrm{b}}$, Jules \\ M. Minke ${ }^{b}$, Jiansheng Yao $^{c}$, Ling He ${ }^{c}$, Robert Nordgren ${ }^{d}$, Ian A. Gardner ${ }^{e}$ and N. James \\ MacLachlan ${ }^{\mathrm{f}}$ \\ ${ }^{a}$ Equine Research Centre, University of Pretoria, Private Bag X04, Onderstepoort 0110, South Africa \\ ${ }^{b}$ Merial S.A.S., R\&D, 254 rue Marcel Merieux, 69007 Lyon, France \\ 'SanofiPasteur, Connaught Campus, 1755 Steeles Avenue West, Toronto, Canada \\ ${ }^{\mathrm{d}}$ Merial Limited, 115 Transtech Drive, Athens, GA 30601, USA \\ e Department of Medicine and Epidemiology, School of Veterinary Medicine, University of California, \\ Davis, CA 95616, USA \\ ${ }^{f}$ Equine Viral Disease Laboratory, Department of Pathology, Microbiology and Immunology, School of \\ Veterinary Medicine, University of California, Davis, CA 95616, USA
}

\begin{abstract}
We describe the development and preliminary characterization of a recombinant canarypox virus vectored $\left(\mathrm{ALVAC}^{\mathbb{B}}\right)$ vaccine for protective immunization of equids against African horse sickness virus (AHSV) infection. Horses $(n=8)$ immunized with either of two concentrations of recombinant canarypox virus vector (ALVAC-AHSV) co-expressing synthetic genes encoding the outer capsid proteins (VP2 and VP5) of AHSV serotype 4 (AHSV-4) developed variable titres $(<10-80)$ of virus-specific neutralizing antibodies and were completely resistant to challenge infection with a virulent strain of AHSV-4. In contrast, a horse immunized with a commercial recombinant canarypox virus vectored vaccine expressing the haemagglutinin genes of two equine influenza H3N8 viruses was seronegative to AHSV and following infection with virulent AHSV-4 developed pyrexia, thrombocytopenia and marked oedema of the supraorbital fossae typical of the "dikkop" or cardiac form of African horse sickness. AHSV was detected by virus isolation and quantitative reverse transcriptase polymerase chain reaction in the blood of the control horse from 8 days onwards after challenge infection whereas AHSV was not detected at any time in the blood of the ALVAC-AHSV vaccinated horses. The control horse seroconverted to AHSV by 2 weeks after challenge infection as determined by both virus neutralization and ELISA assays, whereas six of eight of the ALVAC-AHSV vaccinated horses did not seroconvert by either assay following challenge infection with virulent AHSV-4. These data confirm that the ALVAC-AHSV vaccine will be useful for the protective immunization of equids against African horse sickness, and avoids many of the problems inherent to liveattenuated AHSV vaccines.
\end{abstract}

Keywords: African horse sickness; Canarypox virus; Vaccine; Horses 


\section{Introduction}

African horse sickness virus (AHSV) is the aetiological agent of African horse sickness, a noncontagious, insect-transmitted disease of equids (1) and (2). African horse sickness is enzootic throughout much of sub-Saharan Africa, but substantial incursions have occurred previously into North Africa, the Iberian Peninsula, the Middle East and the Indian subcontinent. The first known reference to a disease resembling African horse sickness was made in Yemen in 1327, and devastating epizootics of the disease occurred regularly following the introduction of horses to southern Africa in 1652 (1). During the epizootic of 1854-1855 70,000 horses reportedly died which at that time was more than $40 \%$ of the horse population of the Cape of Good Hope (3). Live-attenuated (LA) AHSV vaccines were first developed during the 1930s in South Africa (4), and polyvalent cell culture attenuated vaccines are still routinely used for protective immunization of horses in sub-Saharan Africa (5). Inactivated vaccines also have been used to protectively immunize horses against AHSV during incursions of the virus into non-enzootic regions such as the Iberian Peninsula (6).

AHSV is a member of the genus Orbivirus, family Reoviridae (7). Nine serotypes of AHSV have been described (8) and (9). The AHSV genome consists of 10 segments of double-stranded RNA that collectively encode seven structural (VP 1-7) and four non-structural (NS1-3/3A) proteins (10). The AHSV particle consists of an icosahedral core (formed by viral proteins (VP) VP1, VP3, VP4, VP6, and VP7) and an outer capsid composed of VP2 and VP5 (11). The L2 and M5 genes, respectively, encode VP2 and VP5. VP2 contains the major determinants of virus neutralization but VP5 also influences virus neutralization through its conformational interaction with VP2 (12) and (13). A recombinant canarypox virus vector that co-expresses the VP2 and VP5 genes of bluetongue virus (BTV) serotype 17 was recently shown to induce sterilizing immunity in vaccinated sheep (14).

In this study we describe the development and preliminary characterization of a canarypox virus vectored vaccine (ALVAC-AHSV) that co-expresses both outer capsid proteins of AHSV serotype 4. This vaccine appears to offer a viable alternative strategy for vaccination of equids to prevent AHSV infection, one that avoids the problems inherent to LA AHSV vaccines; in particular their potential for variable attenuation, lack of immunogenicity, transmission by vector insects with potential reversion to virulence, and the inability to distinguish vaccinated and naturally infected animals (15), (16), (17) and (18).

\section{Materials and methods}

\subsection{Cells and virus}

Baby hamster kidney cells (BHK-21: ATCC CCL 10) were maintained in Eagle's medium (EMEM) supplemented with 5\% foetal bovine serum (Adcock-Ingram Inc.), 10\% tryptose phosphate broth and $1 \%$ gentamycin. A field strain of AHSV serotype 4 (AHSV-4 Jane) that was originally isolated in 1997 from a dead horse was used throughout these studies (19). The virus was propagated in BHK-21 cells for five serial passages. The virulence of this virus in horses has been confirmed previously (19). 


\subsection{Construction of recombinant canarypox virus that expresses the capsid proteins of AHSV (ALVAC-AHSV)}

Synthetic genes encoding the VP2 and VP5 proteins of AHSV-4 were used in the construction of a recombinant canarypox virus vector. Briefly, the L2 and M5 gene segments that respectively encode VP2 and VP5 were amplified by reverse transcriptase polymerase chain reaction (RTPCR) and sequenced using a previously described protocol (20). The sequences of the L2 and M5 genes of the Jane isolate of AHSV-4 were compared to the published sequences of the same genes of other strains of AHSV-4 available at GenBank ${ }^{\circledR}$, and optimized synthetic sequences were then derived using GENEOPTIMIZER ${ }^{\circledR}$ software (Geneart GmbH) for chemical synthesis of an array of oligonucleotides that encompass each individual gene. The oligonucleotides were assembled using a PCR-based strategy to generate the complete, full length synthetic VP2 and VP5 coding sequences. The synthetic genes encoding VP2 and VP5 were then subcloned into the canarypox virus vector to produce the AHSV-canarypox virus recombinant (ALVAC-AHSV), essentially as previously described for the recombinant canarypox virus vectored West Nile virus (RECOMBTITEK ${ }^{\circledR}$ WNV) vaccine (21). Briefly, the synthetic gene encoding VP2 of AHSV-4 was subcloned into a canarypox $\mathrm{C} 3$ insertion vector (plasmid containing a vaccinia virus $\mathrm{H} 6$ promoter and the flanking arms of the canarypox C3 locus) to generate an expression cassette consisting of the VP2 gene under the control of the H6 promoter. Subsequently, an expression cassette consisting of the synthetic VP5 gene under the control of entomopoxvirus Amsacta moorei $42 \mathrm{~K}$ promoter was constructed and cloned into the H6-VP2 donor plasmid. The resultant insertion plasmid contains two expression cassettes, the VP2 gene being under the control of the H6 promoter and the VP5 gene being under the control of the $42 \mathrm{~K}$ promoter, in a tail to head orientation (Fig. 1). To generate ALVAC-AHSV, the insertion plasmid was transfected into primary chicken embryo fibroblast cells that were subsequently infected with canarypox virus. After $24 \mathrm{~h}$, the transfected-infected cells were harvested, sonicated and used for recombinant virus screening (22). The recombinant plaques were screened by in situ plaque lift hybridization method using an AHSV-specific probe. After four sequential rounds of plaque purification, the recombinant confirmed by hybridization as $100 \%$ positive for the AHSV insert was amplified and used to prepare vaccine stocks (identified as vCP2377) that were stored at $-80^{\circ} \mathrm{C}$. Expression of VP2 in ALVAC-AHSV infected cells was evidenced by western immunoblotting using a mixture of anti-VP2-specific guinea pig polyclonal sera (generated with mixtures of VP2 peptides) and expression of VP5 was detected by western immunoblotting using the anti-VP5 specific monoclonal 10AE12 (INGANASE, Madrid, Spain). 


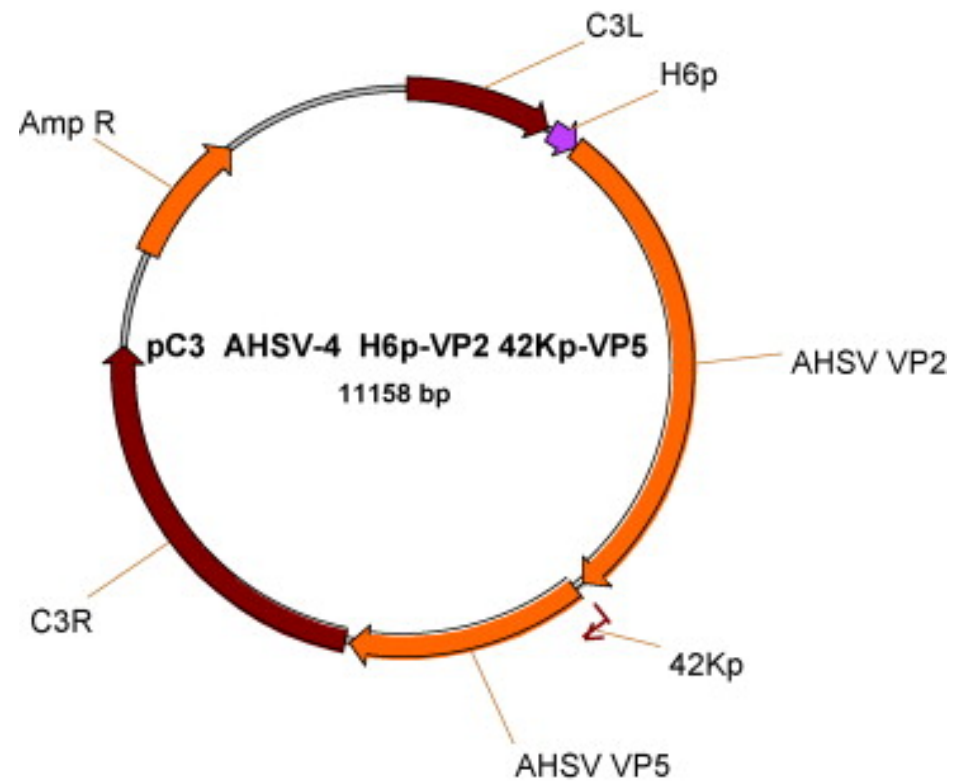

Fig. 1. Structure of the C5 locus donor plasmid containing the tandem expression cassette for the African horse sickness virus (AHSV) VP2 and VP5 proteins. AmpR: ampicillin resistance; C3R: right arm sequence of ALVAC C3 locus; C3L: left arm sequence of ALVAC C3 locus; H6p: vaccinia virus H6 promoter; 42Kp: Amsacta moorei entomopoxvirus $42 \mathrm{~K}$ promoter; synthetic AHSV VP2: codon optimized African horse sickness virus VP2; synthetic AHSV VP5: codon optimized African horse sickness virus VP5.

\subsection{Vaccination of horses with ALVAC-AHSV}

Nine yearling Boerperd horses (five colts, four fillies) were procured from the Northern Cape Province, South Africa, a region free from reported AHS for at least the preceding 12 months. The horses were confirmed to be free of AHSV-specific antibodies by indirect enzyme-linked immunosorbent assay (ELISA) that detects antibodies to the VP7 core protein that is common to viruses of the AHSV serogroup (23). The horses were housed in vector-protected, isolation facilities at the University of Pretoria throughout these studies, and all procedures were approved by the University of Pretoria Animal Use and Care Committee. Two groups of four horses each (two males and two females) were inoculated intramuscularly with $10^{7.1}$ or $10^{6.4} \mathrm{TCID}_{50}$, respectively, of ALVAC-AHSV in approximately $1 \mathrm{ml}$ of diluent containing a Carbopol ${ }^{\circledR}$ 974P adjuvant (BF Goodrich). For ethical reasons, only a single control horse was used to confirm the virulence of the challenge inoculum because this virus strain has previously been shown to cause severe or lethal disease in inoculated horses (19). The control horse was vaccinated with ALVAC-EIV expressing the haemagglutinin proteins of two equine influenza H3N8 viruses (PROTEQFLU, Merial) that was administered according to the manufacturer's instructions (24). All horses were revaccinated 28 days later with the respective vaccine construct. The animals were co-housed regardless of vaccine type. All laboratory testing was done independent of knowledge of vaccination status. 


\subsection{AHSV infection of horses and sample collection}

All nine horses were challenged by intravenous inoculation of $10^{5.5}$ TCID $_{50}$ of AHSV-4 at 28 days after the second vaccination (week 8). Rectal temperatures, heart rates, respiratory rates and habitus of horses were evaluated daily for manifestations of African horse sickness for 23 days after inoculation. Horses were considered as being pyrexic if the rectal temperature was $39{ }^{\circ} \mathrm{C}$ or above. Blood was collected in EDTA VACUTAINER ${ }^{\circledR}$ tubes prior to challenge infection and at $2,5,7,9,12,14$ and 16 for the control and the vaccinates and 19, 21 and 23 days post-infection (DPI) for the control horse for haematological analysis. Blood samples were also collected daily in EDTA VACUTAINER ${ }^{\circledR}$ tubes on days 0 through 23 DPI for quantitative reverse transcriptase real-time polymerase chain reaction (RT-qPCR) and virus isolation in BHK-21 cells. Serum was collected in SST ${ }^{\mathrm{TM}}$ serum separator tubes from all horses immediately prior to vaccination and at two weekly intervals thereafter.

\subsection{Clinical laboratory assays}

Haematological analysis, which included platelet counts, was done at the Clinical Pathology Laboratory at the Onderstepoort Veterinary Academic Hospital, University of Pretoria, with an electronic cell counter (Coulter Electronics Inc.).

\subsection{Virus detection}

Virus isolation from blood was done in BHK-21 cells, as previously described (20). The presence of AHSV in the blood of the horses was determined using RT-qPCR assays that detect the individual genes encoding the VP7 and NS2 proteins of AHSV with samples being classified as positive if the fluorescence exceeded the threshold of 0.1 within a maximum of 40 cycles (Quan et al., unpublished data).

\subsection{Serological assays}

Serotype-specific neutralizing antibodies to AHSV were detected by microneutralization assay using AHSV-4 as the challenge virus as previously described (25). Antibody titres were recorded as the reciprocal of the highest final dilution of serum that provided at least $50 \%$ protection of the BHK-21 cell monolayer. A titre of $>10$ was considered positive and a 4-fold increase in titre was considered as seroconversion. Group-specific antibodies to AHSV were detected by an indirect enzyme-linked immunosorbent assay (ELISA) that detects antibodies to the VP7 core protein that is common to viruses of the AHSV serogroup as previously described (23).

\subsection{Statistical analysis}

AHSV-4 neutralizing antibody titres at just prior to AHSV infection were compared between the vaccine groups by Mann-Whitney $U$ test with a $P<0.05$ being considered significant. 


\section{Results}

\subsection{Immunogenicity of ALVAC-AHSV}

A recombinant canarypox virus vector was developed that co-expresses the VP2 and VP5 proteins of AHSV-4. All horses were seronegative by both ELISA and AHSV-4 microneutralization assays prior to vaccination, and all but two horses developed neutralizing antibodies to AHSV-4 after immunization with the ALVAC-AHSV whereas the horse immunized with ALVAC-EIV did not develop neutralizing antibodies to AHSV-4 (Table 1). At 4 weeks following the second vaccination, AHSV-4 titres were significantly higher $(P=0.021)$ in horses given the high vaccine dose than those in the low dose group. All horses remained healthy and showed no adverse effects after vaccination.

Table 1. Titres of African horse sickness serotype 4 neutralizing antibodies.

\begin{tabular}{|c|c|c|c|c|c|c|}
\hline \multirow[t]{2}{*}{$\begin{array}{l}\text { Treatment/horse } \\
\text { ID }\end{array}$} & \multicolumn{3}{|c|}{$\begin{array}{l}\text { Post-vaccination titres }{ }^{\mathrm{a}} \text { (weeks after } \\
\text { primary vaccination) }\end{array}$} & \multicolumn{3}{|c|}{$\begin{array}{l}\text { Post-infection titres (weeks after } \\
\text { AHSV infection) }\end{array}$} \\
\hline & $\mathbf{0}$ & 4 & 8 & 2 & 4 & 6 \\
\hline \multicolumn{7}{|c|}{ Vaccinated (ALVAC-AHSV $-10^{7.1}$ ) } \\
\hline 1 & $<10$ & $<10$ & 28 & 20 & 40 & 20 \\
\hline 2 & $<10$ & $<10$ & 40 & 40 & 10 & 14 \\
\hline 3 & $<10$ & $<10$ & 20 & 40 & 28 & 40 \\
\hline 4 & $<10$ & $<10$ & 40 & 80 & 56 & 80 \\
\hline \multicolumn{7}{|c|}{ Vaccinated (ALVAC-AHSV $\left.-10^{6.4}\right)$} \\
\hline 5 & $<10$ & $<10$ & $<10$ & $<10$ & $<10$ & $<10$ \\
\hline 6 & $<10$ & $<10$ & $<10$ & 10 & $<10$ & $<10$ \\
\hline 7 & $<10$ & $<10$ & 14 & 40 & 20 & 10 \\
\hline 8 & $<10$ & $<10$ & 10 & 56 & 56 & 14 \\
\hline \multicolumn{7}{|c|}{ Control (ALVAC-EIV) } \\
\hline 9 & $<10$ & $<10$ & $<10$ & 10 & 160 & 224 \\
\hline
\end{tabular}

${ }^{a}$ Expressed as the reciprocal of the highest dilution that provided $>50 \%$ protection of the BHK21 cell monolayer. 


\subsection{Protection of horses immunized with ALVAC-AHSV}

The ability of ALVAC-AHSV to protectively immunize horses was evaluated by comparing amounts of AHSV nucleic acid (Cq values) in the blood of ALVAC-AHSV (vaccinates) and ALVAC-EIV (control) immunized horses after challenge infection (Fig. 2). Whereas AHSV nucleic acid was detected from 8 DPI of the control horse (ALVAC-EIV), it was never detected in the blood of the vaccinated horses. Similarly, AHSV-4 was repeatedly isolated from the blood of the control horse but never from the vaccinated horses (data not shown).

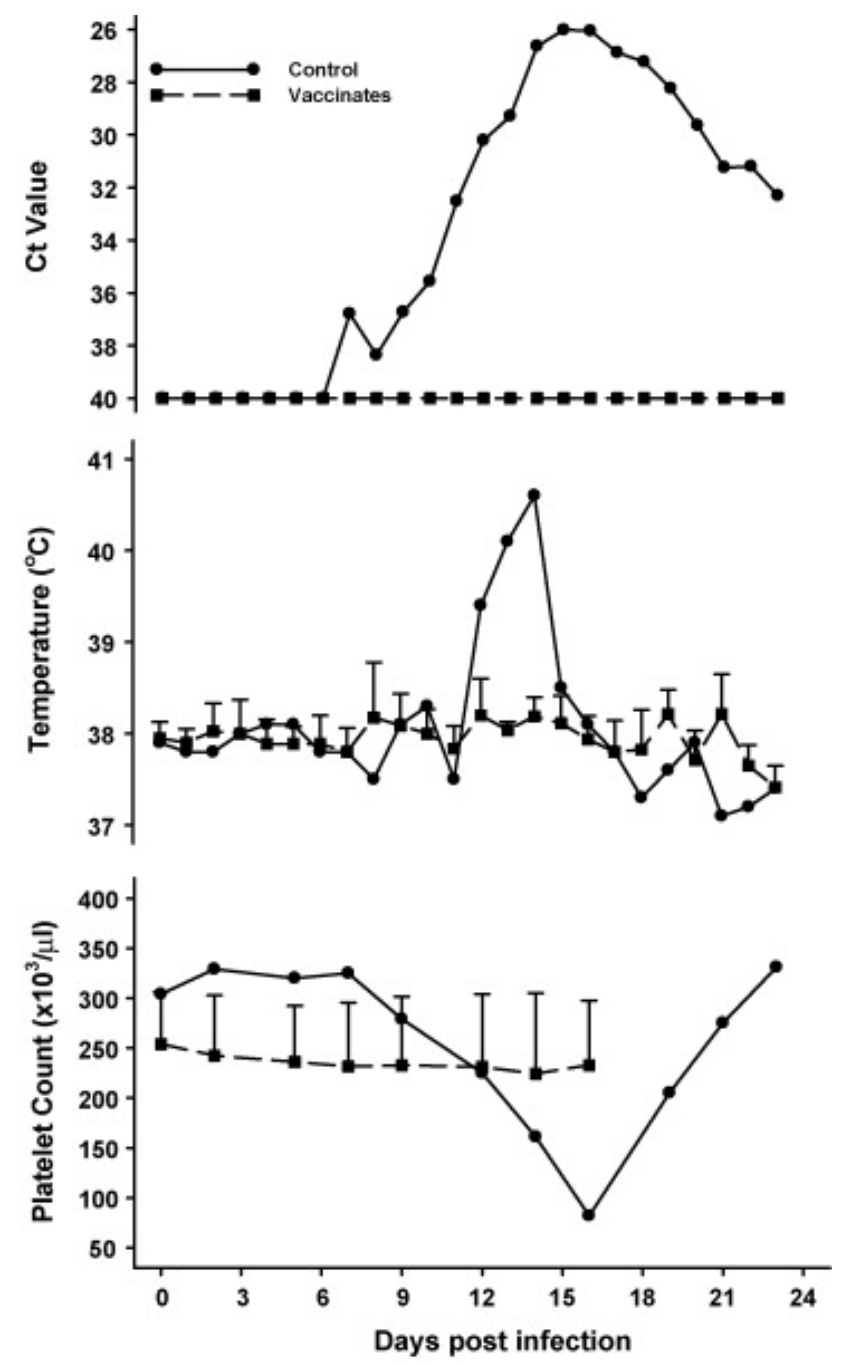

Fig. 2. (A) Mean and standard deviation of quantification cycle (Cq) of RT-qPCR's for genes encoding for AHSV NS2 and VP7 proteins; (B) body temperature; and (C) platelet count of unvaccinated control horse and ALVAC-AHSV vaccinates after challenge with a virulent field strain of AHSV serotype 4. 
The control (ALVAC-EIV) horse developed clinical signs consistent with the so-called "dikkop" or cardiac form of African horse sickness, whereas the vaccinated horses all remained clinically normal throughout the study. Specifically, the control horse was markedly depressed for several days, developed high fever and thrombocytopenia that coincided with increasing viral load in blood whereas none of the vaccinates developed pyrexia or became thrombocytopenic (Fig. 2). The control horse also developed prominent oedema of the supraorbital fossae at 12 DPI, which persisted until 21 DPI. The horse received symptomatic supportive treatment and survived.

\subsection{Serological responses of ALVAC-AHSV vaccinated and control horses after challenge exposure to AHSV-4}

The serological responses of vaccinated (ALVAC-AHSV) and control (ALVAC-EIV) horses were determined following challenge infection with AHSV-4 by both SN (Table 1) and ELISA (data not shown) tests. The control horse seroconverted to AHSV by 2 weeks after challenge, as determined by SN assays, two of the horses in the group that received the low dose of vaccine seroconverted whilst none of the horses in the group that received the high dose of vaccine seroconverted. Furthermore, all the horses vaccinated with the high dose of vaccine remained negative for antibodies to VP7 by ELISA for the duration of the study. Similarly, the AHSV-4 neutralizing antibody after challenge infection in the control (ALVAC-EIV) horse that was seronegative prior to challenge was considerably greater than the titres observed in the vaccinated horses at 4 and 6 weeks after infection.

\section{Discussion}

The recent emergence and extension of occurrence of various arboviral diseases has been ascribed to changes in vector biology associated with climate change (26). The recent occurrence of BTV serotype 8 in northern Europe and its subsequent spread (27), the first recorded occurrence of outbreaks AHSV serotype 2 in Senegal, Nigeria and Ethiopia in 2007 and 2008 (28) and the first recorded outbreak of equine encephalosis outside of Africa in Israel in 2008 (29) suggest that climate change may also result in a change in the epidemiology of AHSV. Consequently, the risk of African horse sickness (AHS) outbreaks may increase in areas traditionally free of the disease, including the Middle East, North Africa and Europe and perhaps other parts of the world.

A variety of vaccines have been developed to prevent AHSV infection of equids, including inactivated and LA virus vaccines, virus like particles (VLPs) produced from recombinant baculoviruses, a recombinant vaccinia vectored vaccine and a DNA vaccine (4), (5), (6), (30), (31), (32), (33), (34) and (35). LA AHSV vaccines were first developed during the 1930s in South Africa (4), and polyvalent mouse brain, or more recently, cell culture attenuated vaccines are used routinely for protective immunization of horses in sub-Saharan Africa (5). These vaccines are cheap and generate a protective immunity after a single inoculation and have proven highly effective in preventing AHS in these areas. However, despite the efficacy of these vaccines, there are a number of limitations including; vaccine reactions (including death) in individual animals, variable immune response in individual animals, difficulty in immunizing young animals with passive maternal immunity, possibility of reversion to virulence of vaccine virus, and recombination of vaccine strains following vaccination with possible reversion to 
virulence (32). Inactivated vaccines are very safe if properly produced, however, they are expensive and may require repeated immunizations (at least twice) because of loss of immunogenicity that ultimately accompanies thorough inactivation (6). Whilst an inactivated vaccine was developed to immunize horses against AHSV-4 during the incursion of the virus into the non-enzootic region of the Iberian Peninsula in the 1980s (6) this vaccine is no longer produced commercially. VLPs are also safe and have been shown to be efficacious in laboratory trials (31), (32), (33) and (34), but they have not been used in the field apparently because of difficulties with commercial production, cost and long-term stability. Recombinant vaccinia viruses expressing VP2 of AHSV serotype 4 induced variable titres of neutralizing antibody in horses and afforded protection against homologous challenge (30), but this approach has apparently not been pursued further. The global emergence of arboviral diseases has highlighted the need for a new generation of AHSV vaccines which are both safe and effective to prevent AHSV infection of equids and vaccines that have properties to allow the differentiation of vaccinated from infected animals (DIVA) would be of particular value if AHSV were to spread into regions that were previously free of AHS.

We describe a recombinant canarypox-vectored vaccine that appears to safely and effectively induce solid protective immunity against AHS serotype 4 in horses. The lack of seroconversion in the horses that received the high dose of vaccine on SN assays and the failure to detect antibody to VP7 by ELISA suggests that virus replication was absent or minimal in these horses and that they developed a sterilizing immunity. The canarypox virus vector is already used in several licensed commercial vaccines worldwide, including for horses (21), (24), (36) and (37). The ALVAC-EIV vaccine contains antigens for two strains of equine influenza virus (24) demonstrating that the ALVAC construct can be used successfully to vaccinate against multiple antigens simultaneously. This property of the construct needs to be further evaluated for the possible development of polyvalent AHSV vaccines. Although polyvalent LA AHSV vaccines have been used previously in the initial emergency response to AHS outbreaks, there are significant potential hazards associated with the use of LA orbivirus vaccines as illustrated by recent experiences with similar BTV vaccines (38) and (39). Although further characterization will be required before the ALVAC-AHSV vaccine, which has DIVA properties, can be used in the field, data from the present study strongly suggest that it offers an attractive alternative to existing LA AHSV vaccines.

\section{Acknowledgements}

The authors gratefully acknowledge Dr. Jannie Crafford, Prof. James Gilkerson, Dr. Wilhemien Ros, Chris Joone, Clifford Matjiane, Mpho Monyai and Lucky Mhlakatshi for assistance with sample collection. We thank Prof. James Gilkerson for reviewing this manuscript and Merial R\&D for their valuable contributions to this study. These studies were supported by funds from Racing South Africa's (Pty) Ltd Equine Research Grant, the Thoroughbred Racing Trust of South Africa and funds provided by the Harriet E. Pfleger Foundation. The Vlampie's SA Boeperd Stud, Irene, South Africa is thanked for making horses available for lease for use in this study.

${ }^{\circledR}$ ALVAC is registered trademark of Connaught Technology Corporation in the United States of America; ${ }^{\circledR}$ GenBank is a registered trademark of the United States Department of Health and 
Human Services in the United States of America; ${ }^{\circledR}$ GENOPTIMIZER is a registered trademark of Geneart AG in the United States of America and elsewhere; ${ }^{\circledR}$ RECOMBITEK WNV is a registered trademark of Merial in the United States of America and elsewhere; ${ }^{\circledR} \mathrm{CARBOPOL}$ is a registered trademark of BF Goodrich in the United States of America and elsewhere; ${ }^{\circledR}$ PROTEQFLU is a registered trademark of Merial in the United States of America and elsewhere; ${ }^{\mathbb{B}}$ VACUTAINER is a registered trademark of Becton, Dickinson and Company in the United States of America and elsewhere; ${ }^{\text {TMSST }}$ is a trademark of Becton, Dickinson and Company.

\section{References}

(1) A. Theiler, African horse sickness (pestis equorum), Sci Bull 19 (1921), pp. 1-29.

(2) A.J. Guthrie, African horse sickness. In: D.C. Sellon and M.T. Long, Editors, Equine infectious diseases, Saunders Elsevier, St. Louis (2007), pp. 164-171.

(3) T.B. Bayley, Notes on the horse-sickness at the Cape of Good Hope in 1854-55, Saul Solomon \& Co., Cape Town (1856).

(4) R.A. Alexander, The immunization of horses and mules against Horsesickness by means of the neurotropic virus of mice and guinea-pigs, Onderstepoort J Vet Sci Anim Ind 2 (1934), pp. 375-391.

(5) B.F. von Teichman and T.K. Smit, Evaluation of the pathogenicity of African Horsesickness (AHS) isolates in vaccinated animals, Vaccine 26 (2008), pp. 5014-5021.

(6) P. Dubourget, J.M. Preaud, N. Detraz, F. Lacoste, A.C. Fabry and B.J. Erasmus et al., Development, production, and quality control of an industrial inactivated vaccine against African horse sickness virus serotype 4. In: T.E. Walton and B.I. Osburn, Editors, Bluetongue, African horse sickness and related orbiviruses, CRC Press, Boca Raton (1992), pp. 874-886.

(7) D.W. Verwoerd, H. Huismans and B.J. Erasmus, Orbiviruses. In: H. Fraenkel-Conrat and R.R. Wagner, Editors, Comprehensive virology, Plenum Press, London (1979), pp. 285-345.

(8) P.G. Howell, The isolation and identification of further antigenic types of African horsesickness virus, Onderstepoort J Vet Res 29 (1962), pp. 139-149.

(9) B.M. McIntosh, Immunological types of horsesickness virus and their significance in immunization, Onderstepoort J Vet Res 27 (1958), pp. 465-539.

(10) M.J. Grubman and S.A. Lewis, Identification and characterization of the structural and nonstructural proteins of African horsesickness virus and determination of the genome coding assignments, Virology 186 (1992), pp. 444-451. 
(11) P. Roy, P.P. Mertens and I. Casal, African horse sickness virus structure, Comp Immunol Microbiol Infect Dis 17 (1994), pp. 243-273.

(12) T.G. Burrage, R. Tevejo, M. Stone-Marschat and W.W. Laegreid, Neutralizing epitopes of African horsesickness virus serotype 4 are located on VP2, Virology 196 (1993), pp. 799-803.

(13) J.L. Martinez-Torrecuadrada and J.I. Casal, Identification of a linear neutralization domain in the protein VP2 of African horse sickness virus, Virology 210 (1995), pp. 391-399.

(14) J.D. Boone, U.B. Balasuriya, K. Karaca, J.C. Audonnet, J. Yao and L. He et al., Recombinant canarypox virus vaccine co-expressing genes encoding the VP2 and VP5 outer capsid proteins of bluetongue virus induces high level protection in sheep, Vaccine 25 (2007), pp. 672-678.

(15) N.J. MacLachlan, U.B. Balasuriya, N.L. Davis, M. Collier, R.E. Johnston and G.L. Ferraro et al., Experiences with new generation vaccines against equine viral arteritis, West Nile disease and African horse sickness, Vaccine 25 (2007), pp. 5577-5582.

(16) C. House, J.A. House and C.A. Mebus, A review of African horse sickness with emphasis on selected vaccines, Ann N Y Acad Sci 653 (1992), pp. 228-232.

(17) J.A. House, Recommendations for African horse sickness vaccines for use in nonendemic areas, Rev Elev Med Vet Pays Trop 46 (1993), pp. 77-81.

(18) J.A. House, Future international management of African horse sickness vaccines, Arch Virol Suppl 14 (1998), pp. 297-304.

(19) J.P. Nurton, A.J. Guthrie and P.G. Howell, Development and preliminary validation of an inactivated African horse sickness virus serotype 4 vaccine, Proceedings of the annual congress of the Equine Practitioners Group of the South African Veterinary Association, vol. 33 (2001), p. 129.

(20) M. Quan, M. Van Vuuren, P.G. Howell, D. Groenewald and A.J. Guthrie, Molecular epidemiology of the African horse sickness virus S10 gene, J Gen Virol 89 (2008), pp. 1159 1168.

(21) J.M. Minke, L. Siger, K. Karaca, L. Austgen, P. Gordy and R. Bowen et al., Recombinant canarypoxvirus vaccine carrying the prM/E genes of West Nile virus protects horses against a West Nile virus-mosquito challenge, Arch Virol Suppl (2004), pp. 221-230.

(22) A. Piccini, M.E. Perkus and E. Paoletti, Vaccinia virus as an expression vector, Methods Enzymol 153 (1987), pp. 545-563.

(23) S. Maree and J.T. Paweska, Preparation of recombinant African horse sickness virus VP7 antigen via a simple method and validation of a VP7-based indirect ELISA for the detection of group-specific IgG antibodies in horse sera, J Virol Methods 125 (2005), pp. 55-65. 
(24) J.M. Minke, C.E. Toulemonde, H. Coupier, P.M. Guigal, S. Dinic and T. Sindle et al., Efficacy of a canarypox-vectored recombinant vaccine expressing the hemagglutinin gene of equine influenza $\mathrm{H} 3 \mathrm{~N} 8$ virus in the protection of ponies from viral challenge, Am $J$ Vet Res 68 (2007), pp. 213-219.

(25) P.G. Howell, D.M. Groenewald, C.W. Visage, A. Bosman, J.A.W. Coetzer and A.J. Guthrie, The classification of seven serotypes of equine encephalosis virus and the prevalence of homologous antibody in horses in South Africa, Onderstepoort J Vet Res 69 (2002), pp. 79-93.

(26) E.A. Gould and S. Higgs, Impact of climate change and other factors on emerging arbovirus diseases, Trans R Soc Trop Med Hyg 103 (2009), pp. 109-121.

(27) B.V. Purse, H.E. Brown, L. Harrup, P.P. Mertens and D.J. Rogers, Invasion of bluetongue and other orbivirus infections into Europe: the role of biological and climatic processes, Rev Sci Technol 27 (2008), pp. 427-442.

(28) A. Wilson, P.S. Mellor, C. Szmaragd and P.P. Mertens, Adaptive strategies of African horse sickness virus to facilitate vector transmission, Vet Res 40 (2008), pp. 1-16.

(29) ProMED-mail. Equine encephalosis-Israel: 2008. ProMED-mail 2009; 1 April: 20090401.1254. http://www.promedmail.org (accessed 02.04.2009).

(30) M.A. Stone-Marschat, S.R. Moss, T.G. Burrage, M.L. Barber, P. Roy and W.W. Laegreid, Immunization with VP2 is sufficient for protection against lethal challenge with African horsesickness virus Type 4, Virology 220 (1996), pp. 219-222.

(31) M. Scanlen, J.T. Paweska, J.A. Verschoor and A.A. Van Dijk, The protective efficacy of a recombinant VP2-based African horsesickness subunit vaccine candidate is determined by adjuvant, Vaccine 20 (2002), pp. 1079-1088.

(32) M. Du Plessis, M. Cloete, H. Aitchison and A.A. Van Dijk, Protein aggregation complicates the development of baculovirus-expressed African horsesickness virus serotype 5 VP2 subunit vaccines, Onderstepoort J Vet Res 65 (1998), pp. 321-329.

(33) P. Roy, D.H. Bishop, S. Howard, H. Aitchison and B. Erasmus, Recombinant baculovirussynthesized African horsesickness virus (AHSV) outer-capsid protein VP2 provides protection against virulent AHSV challenge, J Gen Virol 77 (1996), pp. 2053-2057.

(34) J.L. Martinez-Torrecuadrada, M. Diaz-Laviada, P. Roy, C. Sanchez, C. Vela and J.M. Sanchez-Vizcaino et al., Full protection against African horsesickness (AHS) in horses induced by baculovirus-derived AHS virus serotype 4 VP2, VP5 and VP7, J Gen Virol 77 (1996), pp. $1211-1221$.

(35) M. Romito, D.H. Du Plessis and G.J. Viljoen, Immune responses in a horse inoculated with the VP2 gene of African horsesickness virus, Onderstepoort J Vet Res 66 (1999), pp. 139-144. 
(36) H. Poulet, J. Minke, M.C. Pardo, V. Juillard, B. Nordgren and J.C. Audonnet, Development and registration of recombinant veterinary vaccines. The example of the canarypox vector platform, Vaccine 25 (2007), pp. 5606-5612.

(37) H. Poulet, S. Brunet, C. Boularand, A.L. Guiot, V. Leroy and J. Tartaglia et al., Efficacy of a canarypox virus-vectored vaccine against feline leukaemia, Vet Rec 153 (2003), pp. 141-145.

(38) ProMED-mail. Bluetongue-Europe (07): BTV-6, BTV-11 update. ProMED-mail 2009; 4 March: 20090304.0888. http://www.promedmail.org (accessed 26.04.2009).

(39) G. Savini, N.J. MacLachlan, J.M. Sanchez-Vizcaino and S. Zientara, Vaccines against bluetongue in Europe, Comp Immunol Microbiol Infect Dis 31 (2008), pp. 101-120. 